\title{
TRANSINGUINAL PREPERITONEAL REPAIR (TIPP) VERSUS LICHTENSTEIN'S REPAIR FOR INGUINAL HERNIA- A COMPARATIVE STUDY
}

\author{
Faisal Moin Ansari' ${ }^{1}$ Chandra Shekhar², Osman Musa ${ }^{3}$, Hira Shuaib ${ }^{4}$ \\ 1 Junior Resident, Department of Surgery, Era's Lucknow Medical College, Lucknow. \\ ${ }^{2}$ Assistant Professor, Department of Surgery, Era's Lucknow Medical College, Lucknow. \\ 3Professor, Department of Surgery, Era's Lucknow Medical College, Lucknow. \\ ${ }^{4}$ Tutor, Department of Physiology, GCRG IMS and Hospital, Lucknow.
}

\begin{abstract}
\section{BACKGROUND}

The concept of preperitoneal repair of inguinal hernia was an effort by Stoppa to reduce the high recurrence rates associated with anterior repairs popular at that time, most of the techniques were tissue based as against prosthetic repair. The Transinguinal Preperitoneal (TIPP) Procedure has been described as an alternative open preperitoneal mesh repair. Our study compared inguinal hernia repair by open transinguinal preperitoneal repair with Lichtenstein's repair.
\end{abstract}

\section{MATERIALS AND METHODS}

A total of 80 patients was included in this study with 40 patients in each group. Both the groups were operated under spinal anaesthesia and by a single competent surgeon. Randomisation was done through computerised random number generation. Both the procedures were performed as per standard guidelines.

\section{RESULTS}

The proportional differences in age groups of patients in both the groups was not statistically significant. Proportion of patients with left inguinal hernia was higher in Group I (35.00\%) as compared to Group II (32.50\%), but this difference was not statistically significant. Mean duration of surgery in Group I ( $60.00+13.25$ minutes) was found to be higher than that in Group II (54.00 + 8.49 minutes). This difference was found to be statistically significant $(p=0.018)$.

\section{CONCLUSION}

Transinguinal preperitoneal mesh repair and Lichtenstein repair methods are comparable surgical techniques with respect to intraoperative as well as post-operative outcomes.

\section{KEYWORDS}

Transinguinal Preperitoneal Repair, Inguinal Hernia, Lichtenstein's Repair.

HOW TO CITE THIS ARTICLE: Ansari FM, Shekhar C, Musa O, et al. Transinguinal Preperitoneal Repair (TIPP) versus Lichtenstein's repair for inguinal hernia- a comparative study. J. Evolution Med. Dent. Sci. 2017;6(39):3139-3142, DOI: $10.14260 /$ Jemds $/ 2017 / 677$

\section{BACKGROUND}

The incidence of inguinal hernias in adult men reported to be $15 \%$ and hernia repair is considered to be the most common surgical procedure performed by general surgeons. In General Surgery, mesh repair of inguinal hernia is the most common operation performed.(1) The concept of preperitoneal repair of inguinal hernia was an effort by Stoppa to reduce the high recurrence rates associated with anterior repairs popular at that time, most of the techniques were tissue based as against prosthetic repair.(2) The advent of tension free prosthetic repairs had competently reduced the recurrence rates to a range of $1 \%$ to $2 \%$. The evolution of preperitoneal approach for recurrent inguinal hernia repair made it the procedure of choice for the management of all recurrent groin hernias, which can be done either laparoscopically or by open method.(3)

Financial or Other, Competing Interest: None.

Submission 09-04-2017, Peer Review 03-05-2017,

Acceptance 09-05-2017, Published 15-05-2017.

Corresponding Author:

Chandra Shekhar,

Assistant Professor

Department of Surgery,

Era's Lucknow Medical College, Lucknow.

E-mail: csr13582@gmail.com

DOI: $10.14260 /$ jemds $/ 2017 / 677$

The Transinguinal Preperitoneal (TIPP) Procedure has been described as an alternative open preperitoneal mesh repair. Our study compared inguinal hernia repair by open transinguinal preperitoneal repair with Lichtenstein's repair.

\section{MATERIALS AND METHODS}

This randomised controlled study was conducted on the patients with a diagnosis of inguinal hernia admitted in the Department of General Surgery at Era's Lucknow Medical College and Hospital, Lucknow from October 2014 to March 2016 (18 months). Minimum sample size of 60 patients (30 patients in each group) was calculated by the Department of Social and Preventive Medicine, Era's Lucknow Medical College using appropriate statistical tools with $80 \%$ power of the study.

Sample Size is calculated on the basis of Variation in Duration of Complete Relief using the Formula-

$\underline{\mathrm{n}}=(\mathrm{Z} \alpha+\mathrm{Z} \beta) 2\left(\left[\begin{array}{ll}\delta & 1\end{array}\right] 2+\left[\begin{array}{ll}\delta & 2\end{array}\right] 2\right)$

$\mathrm{d} 2$

Where

$\delta 1=2.01$

$\delta 2=1.6$

The SD of duration of complete relief in the two groups. 
$\mathrm{D}=1.6$

Type 1 error $\alpha=5 \%$

Type 2 error $\beta=20 \%$ for detecting results with $80 \%$ power of study

Data loss $=10 \%$

The sample size comes out to be

$\mathrm{N}=30$ in each group

To increase the confidence and power of study, the sample size was kept as 80 patients ( 40 patients in each group) falling in sampling frame were enrolled in the study. They were randomly allocated to one of the following two groups:

Group I $(n=40)$ : Patients in this group underwent hernia repair using open preperitoneal mesh procedure. Group II $(n=40)$ : Patients in this group underwent hernia repair using Lichtenstein procedure. Randomisation was done through computerised random number generation. Both the procedures were performed as per standard guidelines. Patients aged above 18 years for elective hernia repair by either technique with either Direct or an Indirect Hernia or both were included in this study. Bilateral and recurrent hernia, other comorbid conditions contraindicating surgery excluded. Both the groups were operated under spinal anaesthesia and by a single competent surgeon. All patients were followed 6 months postoperatively.

Lichtenstein's repair was done as per established technique and standard protocol. In Transinguinal Preperitoneal technique (TIPP), incision is the same as that in the Lichtenstein's technique. After dissection of the sac, the transversalis fascia is incised in the line of skin incision to enter into preperitoneal space developed by blunt dissection. The preperitoneal space extends from rectus muscle medially, arcuate line cranially, a little beyond the anterior superior iliac spine over the psoas muscle laterally and the iliopubic tract caudally. A 6" $\times 6 "$ polypropylene mesh trimmed in a semicircular fashion to prevent trauma to the bladder neck, placed in this preperitoneal space and anchored to the Cooper's ligament with a single 2 - 0 interrupted polypropylene suture.

\section{Statistical Analysis}

All statistical analysis was performed using Microsoft Excel computer program. Descriptive data was analysed by nonparametric test; Fisher exact chi-square test and quantitative data analysed using the unpaired student's t-test.

\section{RESULTS}

Patients included in the study were aged between 20 and 75 years. Proportional differences in age groups of patients in both the groups was not statistically significant. Mean age (see Table 1) of patients in the present study was 44.10 \pm 17.47 years, while that in Group I and Group II was $42.85 \pm 18.44$ years and $45.35 \pm 16.59$ years respectively. Out of 80 patients with inguinal hernia (see Table 2), 53 (66.25\%) were diagnosed as right inguinal hernia and rest 27 (33.75\%) as left inguinal hernia. The proportion of patients with left inguinal hernia was higher in Group I (35.00\%) as compared to Group II (32.50\%), but this difference was not statistically significant. In overall study population (81.25\%) as well as in Group I (82.50\%) and Group II (80.00\%) of the study, no history of straining (see Table 3) was observed in the majority of the cases. Though the proportion of straining was higher in Group II (20.00\%) as compared to Group I $(17.50 \%)$, but this difference was not statistically significant ( $p=0.775$ ). Chronic pain (see Table 4) was found in $28.75 \%$ of total patients, though the chronic pain was found in higher proportion of patients of Group II (30.0\%) as compared to Group I (22.50\%), but this difference was not statistically significant. Seroma was present in only $6.25 \%$ of total population. The incidence of seroma in Group I (7.50\%) was found to be higher than that in Group II $(5.00 \%)$, but the difference was not statistically significant ( $\mathrm{p}=0.644)$.

Duration of surgery (see Table 5) in overall population and Group I ranged from 35 - 90 minutes, while that in Group II it was 40 - 80 minutes and the median duration of surgery in overall population as well as in Group I and Group II was 55 minutes. Mean duration of surgery in Group I (60.00 \pm 13.25 minutes) was found to be higher than that in Group II $(54.00+8.49$ minutes); this difference was found to be statistically significant $(\mathrm{p}=0.018)$. The cost of surgery (see Table 6) in Group I ranged from Rs. 4000 - 5400, while that in Group II was Rs. 4000 - 5100. The median cost of surgery in overall population as well as in both the Group was 4500/-. The difference in mean cost of surgery of Group I (Rs. $4521.00 \pm 315.54$ ) and Group II (Rs. $4537.50+329.48$ ) was not found to be statistically significant.

Duration of hospital stay (see Table 7) in overall population as well as in both the groups ranged between 3 and 9 days. The median duration was 5 days. Though, the mean duration of hospital stay was higher in Group I (5.20 \pm 1.45 days) as compared to that in Group II (5.13 \pm 1.67 days), but this difference was not found to be statistically significant $(\mathrm{p}=0.831$ ). Duration of return to work in overall population as well as in Group I was 7 to 14 days, while that in Group II was 7 to 13 days. Median duration to return to work in both the groups as well as in overall population was 9 days. Mean duration to return to work in Group II ( $9.20 \pm 1.87$ days) was found to be higher than that of Group I ( $9.15 \pm 1.69$ days), but the difference was not statistically significant $(p=0.900)$.

\begin{tabular}{|c|c|c|c|c|c|c|}
\hline \multirow{2}{*}{$\begin{array}{c}\text { Age } \\
\text { Group }\end{array}$} & \multicolumn{2}{|c|}{ Total $(\mathrm{N}=80)$} & \multicolumn{2}{|c|}{$\begin{array}{l}\text { Group I } \\
(n=40)\end{array}$} & \multicolumn{2}{|c|}{$\begin{array}{c}\text { Group II } \\
(n=40)\end{array}$} \\
\hline & No. & $\%$ & No. & $\%$ & No. & $\%$ \\
\hline Up to 30 & 25 & 31.25 & 15 & 37.50 & 10 & 25.00 \\
\hline $31-40$ & 12 & 15.00 & 4 & 10.00 & 8 & 20.00 \\
\hline $41-50$ & 10 & 12.50 & 6 & 15.00 & 4 & 10.00 \\
\hline $51-60$ & 15 & 18.75 & 6 & 15.00 & 9 & 22.50 \\
\hline $61-70$ & 16 & 20.00 & 7 & 17.50 & 9 & 22.50 \\
\hline \multirow[t]{2}{*}{$71-80$} & 2 & 2.50 & 2 & 5.00 & 0 & 0.00 \\
\hline & \multicolumn{6}{|c|}{$\chi^{2}=5.583(\mathrm{df}=5) ; \mathrm{p}=0.349$} \\
\hline $\begin{array}{l}\text { Min.-Max. } \\
\text { (Median) }\end{array}$ & \multicolumn{2}{|c|}{$20-75(44)$} & \multicolumn{2}{|c|}{$20-75(43.50)$} & \multicolumn{2}{|c|}{$20-70(45.50)$} \\
\hline Mean \pm SD & \multicolumn{2}{|c|}{$44.10 \pm 17.47$} & \multicolumn{2}{|c|}{$42.85 \pm 18.44$} & \multirow{2}{*}{\multicolumn{2}{|c|}{$45.35 \pm 16.59$}} \\
\hline & Tal & Co & ariso & of Age & & \\
\hline
\end{tabular}

\begin{tabular}{|c|c|c|c|c|c|c|}
\hline \multirow{2}{*}{ Diagnosis } & \multicolumn{2}{|c|}{$\begin{array}{c}\text { Total } \\
(\mathbf{N = 8 0})\end{array}$} & \multicolumn{2}{c|}{$\begin{array}{c}\text { Group I } \\
(\mathbf{n = 4 0 )}\end{array}$} & \multicolumn{2}{c|}{$\begin{array}{c}\text { Group II } \\
(\mathbf{n = 4 0 )}\end{array}$} \\
\cline { 2 - 7 } & No. & $\mathbf{\%}$ & No. & $\mathbf{\%}$ & No. & $\%$ \\
\hline $\begin{array}{c}\text { Left Inguinal } \\
\text { Hernia }\end{array}$ & 27 & 33.75 & 14 & 35.00 & 13 & 32.50 \\
\hline $\begin{array}{c}\text { Right Inguinal } \\
\text { Hernia }\end{array}$ & 53 & 66.25 & 26 & 65.00 & 27 & 67.50 \\
\hline \multicolumn{6}{|c|}{$\chi^{2}=0.056(\mathrm{df}=1) ; \mathrm{p}=0.813$} \\
\hline \multicolumn{3}{|c|}{ Table 2. Comparison of Diagnosis } \\
\hline
\end{tabular}




\begin{tabular}{|c|c|c|c|c|c|c|}
\hline \multirow{2}{*}{ Risk Factors } & \multicolumn{2}{|c|}{ Total (N=80) } & \multicolumn{2}{c|}{$\begin{array}{c}\text { Group I } \\
(\mathbf{n = 4 0 )}\end{array}$} & \multicolumn{2}{c|}{$\begin{array}{c}\text { Group II } \\
(\mathbf{n = 4 0 )}\end{array}$} \\
\cline { 2 - 7 } & No. & $\mathbf{\%}$ & No. & \% & No. & \% \\
\hline $\begin{array}{c}\text { No history of } \\
\text { straining }\end{array}$ & 65 & 81.25 & 33 & 82.50 & 32 & 80.00 \\
\hline $\begin{array}{c}\text { History of } \\
\text { straining }\end{array}$ & 15 & 18.75 & 7 & 17.50 & 8 & 20.00 \\
\hline \multicolumn{6}{|c|}{$\chi^{2}=0.082(\mathrm{df}=1) ; \mathrm{p}=0.775$} \\
\hline \multicolumn{6}{|c|}{ Table 3. Comparison of Risk Factors } \\
\hline
\end{tabular}

\begin{tabular}{|c|c|c|c|c|c|c|c|c|}
\hline & \multicolumn{2}{|c|}{$\begin{array}{c}\text { Total } \\
(\mathbf{N}=\mathbf{8 0})\end{array}$} & \multicolumn{2}{c|}{$\begin{array}{c}\text { Group I } \\
(\mathbf{n = 4 0 )}\end{array}$} & \multicolumn{2}{c|}{$\begin{array}{c}\text { Group II } \\
\mathbf{( n = 4 0 )}\end{array}$} & $\begin{array}{c}\text { Statistical } \\
\text { Significanc } \\
\mathbf{e}\end{array}$ \\
\cline { 2 - 9 } & No. & $\mathbf{\%}$ & No. & $\mathbf{\%}$ & No. & $\mathbf{\%}$ & $\chi^{\mathbf{2}}$ & $\mathbf{p}$ \\
\hline Chronic Pain & 23 & 28.75 & 9 & 22.50 & 14 & 30.00 & 1.526 & 0.217 \\
\hline Recurrence & 0 & 0.00 & 0 & 0.00 & 0 & 0.00 & - & - \\
\hline Seroma & 5 & 6.25 & 3 & 7.50 & 2 & 5.00 & 0.213 & 0.644 \\
\hline Table 4. Comparison of Late Post-Operative Complications \\
\hline
\end{tabular}

\begin{tabular}{|c|c|c|c|c|c|c|}
\hline Group & $\begin{array}{c}\text { No. of } \\
\text { Patients }\end{array}$ & Min. & Max. & Median & Mean & S.D. \\
\hline Group I & 40 & 35 & 90 & 55 & 60.00 & 13.25 \\
\hline Group II & 40 & 40 & 80 & 55 & 54.00 & 8.49 \\
\hline Total & 80 & 35 & 90 & 55 & 57.00 & 11.46 \\
\hline
\end{tabular}

Table 5. Comparison of Duration of Surgery (In Minutes)

\begin{tabular}{|c|c|c|c|c|c|c|}
\hline Group & $\begin{array}{c}\text { No. of } \\
\text { Patients }\end{array}$ & Min. & Max. & Median & Mean & S.D. \\
\hline Group I & 40 & 4000 & 5400 & 4500 & 4521.00 & 315.54 \\
\hline Group II & 40 & 4000 & 5100 & 4500 & 4537.50 & 329.48 \\
\hline Total & 80 & 4000 & 5400 & 4500 & 4529.25 & 320.64 \\
\hline \multicolumn{7}{|c|}{ Table 6. Comparison of Total Cost of Surgery } \\
\hline
\end{tabular}

\begin{tabular}{|c|c|c|c|c|c|c|}
\hline Group & $\begin{array}{c}\text { No. of } \\
\text { Patients }\end{array}$ & Min. & Max. & Median & Mean & S.D. \\
\hline Group I & 40 & 3 & 9 & 5 & 5.20 & 1.45 \\
\hline Group II & 40 & 3 & 9 & 5 & 5.13 & 1.67 \\
\hline Total & 80 & 3 & 9 & 5 & 5.16 & 1.55 \\
\hline
\end{tabular}

Table 7. Comparison of Total Duration of Hospital Stay

\section{DISCUSSION}

There are a number of surgical techniques to perform hernia repair, viz. tension-free prosthetic repairs done through anterior approach (Lichtenstein repair, plug repair, patch and plug repair and double-layer devices) or posterior/preperitoneal approach (open technique, Stoppa, laparoscopic/endoscopic repairs) and tissue-suture repairs that include Bassini-Shouldice technique and its modifications and Marcy repair.(4) Subsequent to evolution of Lichtenstein repair, a low-recurrence hernia repair technique, the focus of researchers was shifted towards improvisation of techniques towards reduction of chronic pain following hernia repair.(5) Transinguinal Preperitoneal (TIPP) inguinal hernia repair with soft mesh is reported as a safe anterior approach with a preperitoneal sutureless mesh position by using the annulus internus as an entrance to the preperitoneal space. This open and sutureless technique has a short learning curve and it is also cost-effective compared to the laparoscopic total extraperitoneal technique.(6)

In the present study, age of patients ranged from 20 to 75 years with a mean age of $44.10 \pm 17.47$ years, the majority of patients were above 40 years of age (53.75\%). In general, inguinal hernia affects all ages, but the incidence increases with age. In an epidemiological study from the United States, the incidence of hernia was reported to be maximum in the age group 60 - 74 years. (7) However, in Indian studies age of patients undergoing inguinal hernia repair has been found to be relatively lesser.(8) In our study, the right side was more commonly involved (66.25\%) than the left side (33.75\%). This observation is in agreement with the observations of McIntosh et al (2000),(9) who reported that inguinal hernias are more common on the right than on the left. In this study, $18.75 \%$ patients had a prior history of straining. Straining factors like coughing, lifting of heavy weights, constipation and BPH are major contributing factors for occurrence of hernia. The difference was not statistically significant. No intraoperative haemorrhage, nerve injury or urinary bladder injury was seen in any of the cases in either of two groups. The occurrence of these complications is rare and reported only in a few cases. In a recent study from India, Ray et al $(2014)^{(10)}$ reported vascular injury in one case as the only intraoperative complication. Thus, the findings of the present study support the view that intraoperative complications are minimal in inguinal hernia repair in almost all the procedures. Pukar and Lakhani $(2014)(11)$ in their study showed haematoma formation in only $1 / 475$ (< $0.01 \%)$ patient undergoing Lichtenstein repair and no infection in any case. Lichtenstein technique is known for its low complication and wound infection rates. Maillart et al (2011)(12) also did not report any wound infection or haematoma formation in any of their patients while using TIPP technique along with a permanent memory ring. As far as the higher incidence of numbness associated with Lichtenstein technique, it could be attributed to an increased risk of nerve involvement in the technique. No case of wound healing problem or chronic infection was reported in the early post-operative period in our study.

The incidence of chronic pain rate was lower in TIPP group $(22.5 \%)$ as compared to Lichtenstein group (30\%). Seroma formation rate was slightly higher in TIPP group $(7.5 \%)$ as compared to Lichtenstein group (5\%). However, the difference between two groups was not statistically significant. No case of recurrence was noticed in any group. However, chronic pain rate for TIPP procedure as observed in the present study (22.5\%) was much higher than that reported by Maillart et al (2011)(12) $(4.8 \%)$. This difference might be attributed to the difference in characteristics of patients in two studies. One of the differences between present study and other studies is the definition of late complications. In present study, late complications were defined as complications noted after 30 days and beyond, while other studies reported 6 months or one year postoperatively. One of the limitation of the study was the duration of study, owing to which most of the patients included in the assessment had a follow-up duration of less than one year and hence the chronic complications in the present study should be viewed within this limitation.

Duration of surgery was slightly (6 mins.), but significantly $(p=0.018)$ longer in TIPP group (60 mins.) as compared to Lichtenstein group (54 mins.). Muldoon et al (2004)(13) while comparing Lichtenstein technique to anterior preperitoneal prosthetic mesh placement also found the latter technique to be 9 mins. longer than the former. 
There is still no sufficient evidence available regarding the superiority of either technique with respect to the duration of surgery and it seems to be dependent on factors other than the complexity of either technique. Relatively, shorter duration of Lichtenstein surgery as observed in the present study and in some previous studies too might be attributed to the fact that Lichtenstein technique is a popular hernia repair technique and the surgical time for TIPP might be longer during the initial learning period. There was no difference in material costs and indirect costs. The present study was carried out in a charitable hospital, where the overall cost of procedures included only the material costs. In our study, no significant difference was observed with respect to time to return to work and hospital stay. Contrary to this, Koning et al $(2012)^{(14)}$ reported a shorter time to return to work in TIPP group as compared to Lichtenstein group. They attributed this difference as a result of reduced pain in TIPP group as compared to Lichtenstein group. Similarly, while comparing extraperitoneal preperitoneal laparoscopic technique (TEP) with Lichtenstein hernioplasty, Kauhia et al (2009)(15) also reported shorter time taken for the return to work in TEP group as compared to Lichtenstein group, which might be attributed to use of the laparoscopic technique in TEP group. Our study found both the techniques comparable except for duration of surgery, which in itself can be improved with the cumulative practice of transinguinal preperitoneal approach for hernia repair. In fact, the shorter duration of followup and small sample size were two limitations in clear demonstration of differences between two techniques. The success of a procedure depends on the longterm sustainable outcome. Moreover, in view of the low complication rate of already existing technique, it is difficult to differentiate a better technique with a small sample, hence further studies on the issue are recommended.

\section{CONCLUSION}

Transinguinal preperitoneal mesh repair and Lichtenstein repair methods are comparable surgical techniques with respect to intraoperative as well as post-operative outcomes. Except for a minor difference in duration of surgery, there are no significant differences between two surgical methods; hence, both the modalities can be a choice for a surgeon.

\section{REFERENCES}

[1] Cheek CM, Black NA, Devlin HB, et al. Groin hernia surgery: a systematic review. Ann R Coll Surg Engl 1998;80(Suppl 1):S1-80.

[2] Stoppa RE, Warlaumont CR, Verhaeghe PJ, et al. Prosthetic repair in the treatment of groin hernias. Int Surg 1986;71(3):154-8.
[3] Simons MP, Aufenacker T, Bay-Nielsen M, et al. European hernia society guidelines on the treatment of inguinal hernia in adult patients. Hernia 2009;13(4):343-403.

[4] Kulacoglu H. Current options in inguinal hernia repair in adult patients. Hippokratia 2011;15(3):223-31.

[5] Schumpelick V, Arlt G. Transinguinal preperitoneal mesh-plasty in inguinal hernia using local anesthesia. Chirurg 1996;67(4):419-24.

[6] Koning GG, Koole D, de Jongh MAC, et al. The transinguinal preperitoneal hernia correction vs Lichtenstein's technique; is TIPP top? Hernia 2011;15(1):19-22.

[7] Ruhl CE, Everhart JE. Risk factors for inguinal hernia among adults in the US population. Am J Epidemiol 2007;165(10):1154-61.

[8] Sinha SP, Sinha S. Mesh V/s non mesh hernia repair: comparison of cost effectiveness and return to work among agricultural labourers. Int J Sc Study 2013;1(3):100-6.

[9] Mclntosh A, Hutchinson A, Roberts A, et al. Evidencebased, management of groin hernia in primary care-a systematic review. Fam Pract 2000;17(5):442-7.

[10] Ray R, Kar M, Mukhopadhyay M. Transinguinal preperitoneal technique of inguinal hernioplasty - a better alternative to lichtenstein procedure. J Clin Diagn Res 2014;8(5):NC01-3.

[11] Pukar M, Lakhani D. Combination of liechtenstein repair with herniorrhaphy in open inguinal hernia repair- a prospective observational single center study. J Clin Diagn Res 2014;8(10): NC03-8.

[12] Maillart JF, Vantournhoudt P, Piret-Gerard G, et al. Transinguinal preperitoneal groin hernia repair using a preperitoneal mesh preformed with a permanent memory ring: a good alternative to Lichtenstein's technique. Hernia 2011;15(3):289-95.

[13] Muldoon RL, Marchant K, Johnson DD, et al. Lichtenstein vs anterior preperitoneal prosthetic mesh placement in open inguinal hernia repair: a prospective, randomized trial. Hernia 2004;8(2):98103.

[14] Koning GG, Keus F, Koeslag L, et al. Randomized clinical trial of chronic pain after the transinguinal preperitoneal technique compared with Lichtenstein's method for inguinal hernia repair. BJS 2012;99(10):1365-73.

[15] Kouhia ST, Huttunen R, Silvasti SO, et al. Lichtenstein hernioplasty versus totally extraperitoneal laparoscopic hernioplasty in treatment of recurrent inguinal hernia-a prospective randomized trial. Ann Surg 2009;249(3):384-7. 